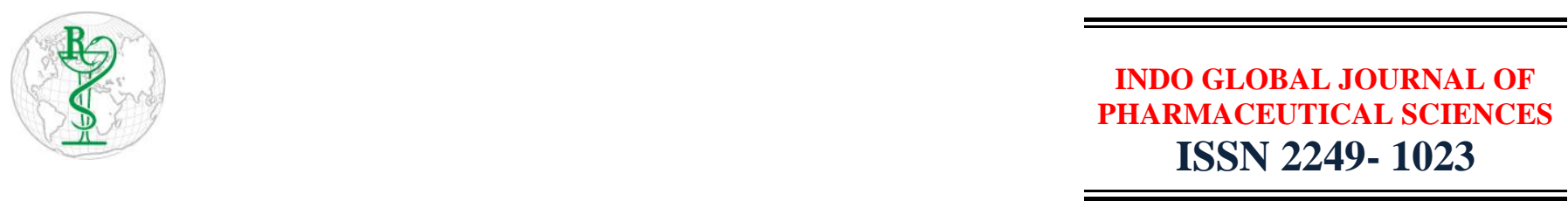

\title{
Role of Synbiotics in Management of Lifestyle Disorders
}

\author{
Rubiya Khursheed *, Ankit Awasthi, Sheetu Wadhwa, Monica Gulati, Sachin Kumar Singh \\ School of Pharmaceutical Sciences, Lovely Professional University, Phagwara, Punjab-144411, India
}

Address for Correspondence: Rubiya Khursheed; rubiyakhursheed141@gmail.com

Received:
01.03.2019
Accepted:
25.03.2019
Keywords
Synbiotics;
Diabetes; Gut
Microbiota;
Obesity.

Received:

Accepted:

Keywords

Synbiotics;

Diabetes; Gut

Obesity.

\begin{abstract}
Gut microflora plays a crucial role in the metabolism of various nutritional substrates for the maintenance of human health. Numerous studies on synbiotics in both non-clinical as well as clinical cases have shown promising results in maintaining the balance of gastrointestinal (GIT) microbiota to improve health conditions. Due to certain conditions such as high fat diet, stress and sedentary lifestyle, bacterial balance may be changed leading to gut dysbiosis and thus manifests in lifestyle disorders such as diabetes, obesity and atherosclerosis. These lifestyle disorders are associated with gut dysbiosis wherein there is increase in gram negative bacteria and decrease in beneficial gram-positive bacteria. The increased level of gram negative bacteria causes increase in lipopolysacharrides (LPS), endotoxemia, diabetes, dyslipidaemia and obesity. It is seen that individuals with increased adiposity and dyslipidaemia are characterized by increased levels of LPS. Synbiotics' administration decreases these LPS and thus decreases inflammation, insulin resistance, diabetes, adiposity and obesity. Synbiotics are also known to influence apetite as well as food intake thereby, treat obesity. Synbiotics manage dyslipidaemia by decreasing cholesterol through inhibiting its intestinal absorption, increasing its excretion and supressing the bile acid reabsorption. The current presentation highlights the role of synbiotics in management of lifestyle disorders and various marketed products containing them. () 2019 iGlobal Research and Publishing Foundation. All rights reserved.
\end{abstract}

Cite this article as: Khursheed, R.; Awasthi, A.; Wadhwa, S.; Gulati, M.; Singh, S.K. Role of synbiotics in Management of Lifestyle Disorders. Indo Global J. Pharm. Sci., 2019; 9(2Suppl.): 112. DOI: http://doi.org/10.35652/IGJPS.2019.92S10 .

Indo Global Journal of Pharmaceutical Sciences( ISSN 2249 1023; CODEN- IGJPAI; NLM ID: 101610675) indexed and abstracted in CrossRef (DOI Enabling), UGC CARE Journal List, EMBASE(Elsevier), National Library of Medicine (NLM) Catalog, ResearchGate, Publons, CAS (ACS), Index Copernicus, Google Scholar and many more. For further details, visit http://iglobaljournal.com

This is a special issue as an outcome of 'RAPSCON-2019' sponsored by APTI and organized by Sri Sai College of Pharmacy, Manawala, Amritsar, Punjab, India. Relaxation offered in journal format. 